\title{
The Denver X-ray Conference - celebrating 65 years of bringing together the high-energy scattering community
}

The year 2016 marks the 100th anniversary of X-ray powder diffraction with the publication of Debye and Scherrer (and soon after Hull), irradiating polycrystalline samples with X-rays and detecting diffraction patterns comprised of "Debye" rings on photographic glass plates. It is also a year to celebrate the 75th anniversary of the International Centre for Diffraction Data ${ }^{\mathrm{TM}}$, ICDD ${ }^{\circledR}$, the 30th anniversary of Powder Diffraction journal, and the 65th anniversary of the Denver X-ray Conference ${ }^{\circledR}$. In writing this editorial it was an opportunity to look at the history of the conference and gain an appreciation for how it has evolved over 65 years.

During the summer of 1951, Professor Isidor Fankuchen was a visiting scientist at the University of Denver, Denver, Colorado, USA. During his brief stay he helped organize a 1 day local symposium, the first Conference on Industrial Applications in X-ray Analysis. Approximately 35 attendees were at this inaugural meeting, with the morning dedicated to fundamentals of X-ray techniques in current research. In the afternoon, six papers were presented by scientists in the local area that were working with X-rays. As the symposium repeated and became the Annual Conference on Industrial Applications in X-ray Analysis, the early organizers felt the purpose of the meeting was to present the latest developments in X-ray absorption, diffraction, and fluorescence analysis, so that these new capabilities could be discussed amongst attendees and workers in the field. This purpose is still evident today, not only for X-ray but also electron and neutron scattering methods.

The first proceedings from the conference were published in 1957, the sixth annual meeting. Thirty papers and two abstracts were published. Of interest is a comment from the Editor William Mueller, noting that the job of putting a proceedings publication together starts with optimism but optimism wanes as the true magnitude of the task becomes apparent. The same can be said for the publication of proceedings in 2016! Today all of the conference proceedings, Advances in X-ray Analysis (AXA), are available on CD-ROM, with Volumes 41-56 ( 1000 papers) available as open access on the ICDD web site (http://www.icdd.com/ resources/axasearch/search_based_on_vol.asp). For 2015, there were 269,612 visits to the ICDD AXA web page, an indication that these published proceedings are actively being used by the scientific community.

Though the name Denver X-ray Conference (DXC) has been used for many years for this meeting, DXC was officially registered in 2000. For many years meeting venues remained in the state of Colorado, until 2014 when Big Sky, Montana was the conference location. This year, another first as DXC moves to the Midwest with Rosemont, Illinois selected as the site for the 65th DXC. Rosemont is located near Chicago and Argonne National Laboratories, providing an excellent opportunity for industrial, government, and academic scientists to be exposed to one of the world's premier user facilities, yet maintain the close knit community that has always been part of the DXC.

In the spirit of the first Denver meeting, this year's DXC (1-5 August 2016) will start with 2 days of workshops covering beginning, intermediate, and advanced topics, and will also have evening poster sessions, a plenary session covering Imaging at Current and Next Generation Synchrotrons, and 3 days of technical sessions. There is also an opportunity to visit Argonne National Laboratory Advanced Photon Source on Sunday July 31st. DXC also provides an excellent opportunity to visit with instrument, software, and component vendors where individuals can see equipment and software demonstrations as well as ask questions specific to analysis needs. Check out the meeting program at the conference web site, http:// www.dxcicdd.com/16/program.htm, and the program is also included in this June issue of Powder Diffraction.

I close by acknowledging two individuals I have had the privilege to be associated with as part of the DXC. Paul Predecki and Victor Buhrke, both served as organizing committee chairs for DXC. I enjoyed our collaborations and thank both of you for your guidance in helping to make DXC the premier meeting for practical applications of $\mathrm{X}$-ray, electron, and neutron analysis.

I look forward to seeing everyone in Rosemont!

Tom Blanton Co-chair Denver X-ray Organizing Committee Principal Scientist International Centre for Diffraction Data 